\title{
Theoretical and experimental investigation of accurately turning the TI worm tooth surface
}

\author{
Yonghong $\mathrm{CHEN}^{*}$,***, Yan $\mathrm{CHEN}^{* *}$, Wenjun $\mathrm{LUO}^{*}$ and Guanghui $\mathrm{ZHANG}^{*}$ \\ * State Key Laboratory of Mechanical Transmissions, Chongqing University \\ 174 Shazheng Street, Shapingba, Chongqing, P. R. China \\ E-mail: chenyonghongjc@163.com \\ ** School of Aeronautics \& Astronautics, Sichuan University \\ No.24 South Section 1, Yihuan Road, Chengdu, Sichuan, P. R. China \\ *** School of Mechanical Engineering \& Automation, Xihua University \\ 999 Jinzhou Street, Jinniu District, Chengdu, Sichuan, P. R. China
}

\section{Received 16 March 2015}

\begin{abstract}
The toroidal involute worm (TI worm) drive is composed of an involute gear and an hourglass worm generated by the involute gear surface, and it is of great advantages for power transmission. Because of the difficulty of grinding TI worm tooth surface, the TI worm drive has rarely been used. To solve this problem, an accurately turning method through the hourglass helix for the TI worm tooth surface is proposed. For this accurately turning method, mathematical models are developed, basic equations are derived and turning accuracy is analyzed. A nylon TI worm is turned and the red test of TI worm drive is checked. It is made clear that the proposed accurately turning method is correct and practicable. The study is expected to provide the theoretical and experimental foundation for the future explore the accurately hard turning of TI worm tooth surface.
\end{abstract}

Key words : TI worm, Tooth surface, Turning theory, Experimental

\section{Introduction}

The enveloping hourglass worm drive is characterized with multi-tooth line contact and good lubrication condition, as well as it has a high load-carrying capacity and is widely applied into heavy-duty machinery. There are a number of types of enveloping hourglass worm drives have been investigated, such as the Hindley worm drive(Litvin and Fuentes 2004; Mohan and Shunmugam 2009), the Wildhaber worm drive(Wildhaber 1966), the planar double-enveloping hourglass worm drive(Zhang 1978), the integrated toroidal drive(Yao, Dai et al. 2004; Xu and Huang 2005; Huang and $\mathrm{Xu}$ 2007), the dual-torus double-enveloping hourglass worm drive(Zhao, Kong et al. 2011), the ZN-type hourglass worm drive(Chen and Tsay 2009), the crown worm drive(Chen, Zhang et al. 2013; Chen, Chen et al. 2015) and the toroidal involute worm (TI worm) drive(Wang, Zhan et al. 2002).

Among various hourglass worm drive, the TI worm drive has rarely been used due to the difficulty of grinding TI worm tooth surface(Wang, Zhan et al. 2002). Maki M.(Maki, Okamoto et al. 1995; Okamoto and Maki 1996) confirmed the usefulness of TI worm drive by the TCA and experiment, and analyzed the contact marks with assembling errors and rotation angle errors. Liu H.(Liu 2001) proposed that the TI worm is envelope-finished by the high-precision diamond dressing gear, but the effect of the practical processing is rather not favorable due to the exfoliation of the corundum from the diamond dressing gear. Sun Y.(Sun, Lu et al. 2008; Sun, Lu et al. 2011) investigated the profile of grinding wheel for grinding TI worm tooth surface, and confirmed that the TI worm tooth surface cannot be accurately ground by the grinding wheel. Furthermore, Li H.(Dong, Wang et al. 2012) presented an $\mathrm{NC}$ rough turning method for the enveloping toroidal worm.

Based on the aforementioned researches, an accurately turning method is presented for TI worm tooth surface in this paper. The mathematical model of TI worm is established, and the theory of accurately turning locus is studied. Turning accuracy and roughness are analyzed. A nylon TI worm is turned and the red test is checked to verify the 
correctness of the proposed turning method. The developed accurately turning principle may help us to explore the hard turning of TI worm tooth surface.

\section{Generating of TI worm surface}

\subsection{Coordinate systems}

The TI worm surface $\Sigma^{\mathrm{w}}$ is considered as a conjugate surface, which is generated as an enveloping about a series of involute gear surfaces $\Sigma^{\mathrm{g}}$. The coordinate systems in the enveloping process are shown in Fig. 1.

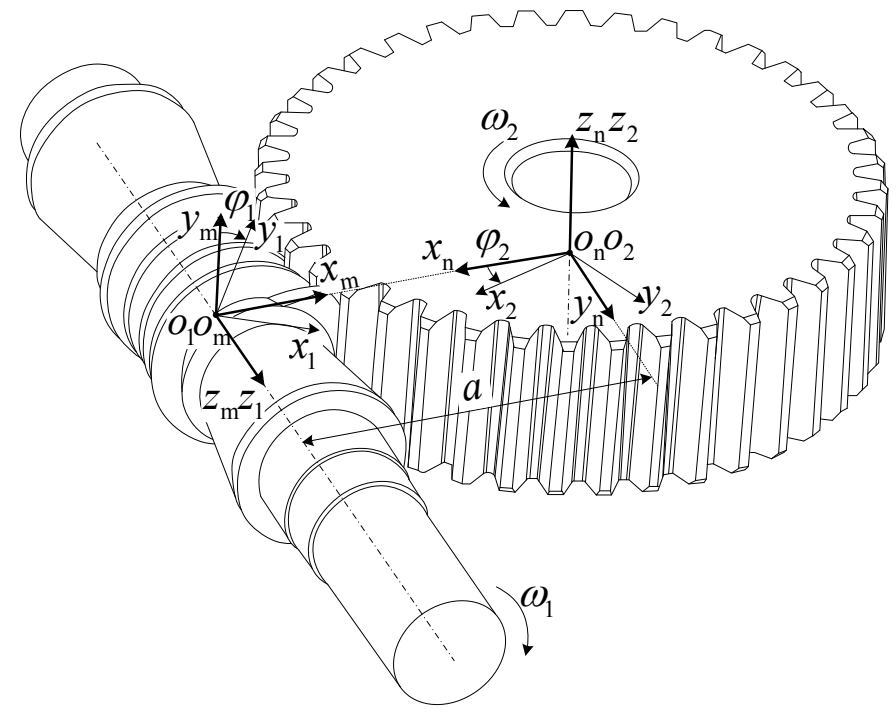

Fig. 1 Coordinate systems in enveloping process

The fixed coordinate systems $\sigma_{\mathrm{m}}\left(o_{\mathrm{m}}: x_{\mathrm{m}}, y_{\mathrm{m}}, z_{\mathrm{m}}\right)$ and $\sigma_{\mathrm{n}}\left(o_{\mathrm{n}}: x_{\mathrm{n}}, y_{\mathrm{n}}, z_{\mathrm{n}}\right)$ indicate the initial position of the TI worm and the involute gear, respectively. The movable coordinate system $\sigma_{1}\left(o_{1}: x_{1}, y_{1}, z_{1}\right)$ is rigidly connected to the TI worm, while $\sigma_{2}\left(o_{2}: x_{2}, y_{2}, z_{2}\right)$ is rigidly connected to the involute gear. The TI worm and the involute gear rotate about axis $z_{1}$ and $z_{2}$ with the angular velocity vectors $\boldsymbol{\omega}_{1}$ and $\boldsymbol{\omega}_{2}$, respectively. The rotating angles are $\varphi_{1}$ and $\varphi_{2}$ at some instant. The shortest distance of axes $z_{\mathrm{m}}$ and $z_{\mathrm{n}}$ is $a$. The unit vector of coordinate systems $\sigma_{\mathrm{m}}, \sigma_{\mathrm{n}}, \sigma_{1}$ and $\sigma_{2}$ are $\left(\boldsymbol{i}_{\mathrm{m}}, \boldsymbol{j}_{\mathrm{m}}, \boldsymbol{k}_{\mathrm{m}}\right),\left(\boldsymbol{i}_{\mathrm{n}}, \boldsymbol{j}_{\mathrm{n}}, \boldsymbol{k}_{\mathrm{n}}\right)$, $\left(\boldsymbol{i}_{1}, \boldsymbol{j}_{1}, \boldsymbol{k}_{1}\right)$ and $\left(\boldsymbol{i}_{2}, \boldsymbol{j}_{2}, \boldsymbol{k}_{2}\right)$, respectively. The directions of rotation correspond to the right-hand TI worm drive in Fig. 1 . When the value of $\boldsymbol{\omega}_{2}$ and $\varphi_{2}$ convert to their opposite number, and the rotating direction of $\boldsymbol{\omega}_{2}$ convert to reverse direction, it will correspond to the left-hand TI worm drive in Fig. 1.

\subsection{Involute gear surface equation}

According to the gear meshing theory, the vector equation of involute gear surface $\Sigma^{\mathrm{g}}$ can be represented in coordinate system $\sigma_{2}$ as follows:

$$
\left.\begin{array}{l}
\boldsymbol{r}^{\mathrm{g}}=x_{2}^{\mathrm{g}} \boldsymbol{i}_{2}+y_{2}^{\mathrm{g}} \boldsymbol{j}_{2}+z_{2}^{\mathrm{g}} \boldsymbol{k}_{2} \\
x_{2}^{\mathrm{g}}=r_{\mathrm{b}} \cos (u+\theta)+r_{\mathrm{b}} \sin (u+\theta) \\
y_{2}^{\mathrm{g}}=r_{\mathrm{b}} \sin (u+\theta)-r_{\mathrm{b}} \cos (u+\theta) \\
z_{2}^{\mathrm{g}}=p \theta
\end{array}\right\}
$$

where $r_{\mathrm{b}}$ is the radius of base circle, $u$ and $\theta$ are the surface variable parameters of $\Sigma^{\mathrm{g}}, p$ is the lead-per-radian revolution of $\Sigma^{\mathrm{g}}$.

\subsection{Meshing equation}

Without losing generality, it is possible to assume the TI worm rotates with angular velocity $\omega_{1}=1 \mathrm{rad} / \mathrm{s}$, and then the involute gear rotates with angular velocity $\omega_{2}=1 / i_{12} \mathrm{rad} / \mathrm{s}$. According to the involute gear surface $\Sigma^{\mathrm{g}}$, the relative velocity vector $\boldsymbol{\nu}^{\mathrm{gw}}$ at the conjugate point can be represented in coordinate system $\sigma_{2}$ as follows: 


$$
\left.\begin{array}{l}
\boldsymbol{v}^{\mathrm{gw}}=v_{x 2}^{\mathrm{gw}} \boldsymbol{i}_{2}+v_{y 2}^{\mathrm{gw}} \boldsymbol{j}_{2}+v_{z 2}^{\mathrm{gw}} \boldsymbol{k}_{2} \\
v_{x 2}^{\mathrm{gw}}=i_{21} y_{2}^{\mathrm{g}}-z_{2}^{\mathrm{g}} \cos \varphi_{2} \\
v_{y 2}^{\mathrm{gw}}=-i_{21} x_{2}^{\mathrm{g}}+z_{2}^{\mathrm{g}} \sin \varphi_{2} \\
v_{z 2}^{\mathrm{gw}}=x_{2}^{\mathrm{g}} \cos \varphi_{2}-y_{2}^{\mathrm{g}} \sin \varphi_{2}-a
\end{array}\right\}
$$

where $i_{21}$ is the teeth ratio, which is the reciprocal of gearing ratio $i_{12}$.

Based on the differential geometry, the unit normal vector of involute gear surface $\Sigma^{\mathrm{g}}$ can be represented in coordinate system $\sigma_{2}$ as following:

$$
\left.\begin{array}{l}
\boldsymbol{n}^{\mathrm{g}}=n_{x 2}^{\mathrm{g}} \boldsymbol{i}_{2}+n_{y 2}^{\mathrm{g}} \boldsymbol{j}_{2}+n_{z 2}^{\mathrm{g}} \boldsymbol{k}_{2} \\
n_{x 2}^{\mathrm{g}}=p r_{\mathrm{b}} \sin (u+\theta) \\
n_{y 2}^{\mathrm{g}}=-p r_{\mathrm{b}} u \cos (u+\theta) \\
n_{z 2}^{\mathrm{g}}=r_{\mathrm{b}}^{2} u
\end{array}\right\}
$$

According to the gear meshing theory, for conjugated action, tooth surface $\Sigma^{\mathrm{g}}$ and $\Sigma^{\mathrm{w}}$ are in tangency during the meshing process. Therefore, the following meshing condition equation should be satisfied:

$$
\Phi=\boldsymbol{v}^{\mathrm{gW}} \boldsymbol{n}^{\mathrm{g}}=0
$$

Substituting $\boldsymbol{\nu}^{\mathrm{gw}}$ and $\boldsymbol{n}^{\mathrm{g}}$ into Eq. (4) with Eqs. (2) and (3), after simplifying, the meshing function can be obtained as following:

$$
\begin{aligned}
\Phi= & \left(p r_{\mathrm{b}} u z_{2} \cos (u+\theta)-r_{\mathrm{b}}^{2} u y_{2}\right) \sin \varphi_{2}-\left(p r_{\mathrm{b}} z_{2} \cos (u-\theta)-r_{\mathrm{b}}^{2} u x_{2}\right) \cos \varphi_{2} \\
& +p r_{\mathrm{b}} i_{21} u x_{2} \cos (u+\theta)+p r_{\mathrm{b}} i_{21} y_{2} \cos (u-\theta)-a r_{\mathrm{b}}^{2} u
\end{aligned}
$$

\subsection{TI worm surface equation}

The TI worm surface $\Sigma^{\mathrm{w}}$ is enveloped by a family of involute gear surface $\Sigma^{\mathrm{g}}$. Using Eqs. (1) and (5), and by coordinate transformation form $\sigma_{2}$ to $\sigma_{1}$, the TI worm surface equation can be derived and represented as following:

$$
\begin{aligned}
& \boldsymbol{r}^{\mathrm{w}}=x_{1}^{\mathrm{w}} \boldsymbol{i}_{1}+y_{1}^{\mathrm{w}} \boldsymbol{j}_{1}+z_{1}^{\mathrm{w}} \boldsymbol{k}_{1} \\
& x_{1}^{\mathrm{w}}=-x_{2}^{\mathrm{g}} \cos \varphi_{1} \cos \varphi_{2}+y_{2}^{\mathrm{g}} \cos \varphi_{1} \sin \varphi_{2}+z_{2}^{\mathrm{g}} \sin \varphi_{1}+a \cos \varphi_{1} \\
& y_{1}^{\mathrm{w}}=x_{2}^{\mathrm{g}} \sin \varphi_{1} \cos \varphi_{2}-y_{2}^{\mathrm{g}} \sin \varphi_{1} \sin \varphi_{2}+z_{2}^{\mathrm{g}} \cos \varphi_{1}-a \sin \varphi_{1} \\
& z_{1}^{\mathrm{w}}=x_{2}^{\mathrm{g}} \cos \varphi_{2}+y_{2}^{\mathrm{g}} \sin \varphi_{2} \\
& x_{2}^{\mathrm{g}}=r_{\mathrm{b}} \cos (u+\theta)+r_{\mathrm{b}} \sin (u+\theta) \\
& y_{2}^{\mathrm{g}}=r_{\mathrm{b}} \sin (u+\theta)-r_{\mathrm{b}} \cos (u+\theta) \\
& z_{2}^{\mathrm{g}}=p \theta \\
& \Phi=0
\end{aligned}
$$

If the values of $\varphi_{2}$ and $u$ are given, a corresponding value of $\theta$ can be obtained from Eq. (5). Substituting the values of $\varphi_{2}, u$ and $\theta$ into Eq. (6), a contact point on $\Sigma^{\mathrm{w}}$ can be determined. If a series of values of $u$ are given, an instantaneous contact line on $\Sigma^{\mathrm{w}}$ can be derived. The TI worm tooth surface $\Sigma^{\mathrm{w}}$ is a family of contact lines with changeable values of $\varphi_{2}$.

\section{Theory of turning tooth surface}

\subsection{Turning locus}

The TI worm tooth surface can be decomposed into a series of hourglass helixes from the tip to the root. The geometric relation of hourglass helix is shown in Fig. 2. 


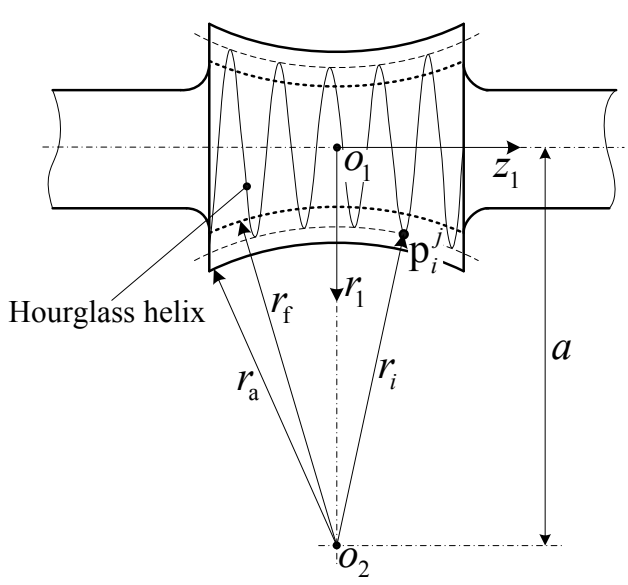

Fig. 2 Geometric relation of hourglass helix

In Fig. 2, $r_{1}$ is the radial value at some point in TI worm tooth surface. $r_{\mathrm{i}}$ is the arc radius of the hourglass helix, and here $r_{\mathrm{a}} \leq r_{\mathrm{i}} \leq r_{\mathrm{f}} . r_{\mathrm{a}}$ and $r_{\mathrm{f}}$ are the arc radius of tip circle and root circle, respectively. Point $p_{\mathrm{i}}^{\mathrm{j}}$ is in the hourglass helix, and the subscript $i$ is the hourglass helix sequence number in tooth surface, and the superscript $j$ is the point sequence number in hourglass helix.

If the coordinate values of point $P_{\mathrm{i}}^{\mathrm{j}}$ in coordinate system $\sigma_{1}$ is $\left(\left(x_{1}{ }^{\mathrm{w}}\right)_{\mathrm{i}}^{\mathrm{j}},\left(y_{1}\right)_{\mathrm{i}}^{\mathrm{w}},\left(z_{1}{ }^{\mathrm{w}}\right)_{\mathrm{i}}^{\mathrm{j}}\right)$, and it must be satisfied the following geometric equation:

$$
\left(r_{i}\right)^{2}-\left(a-\sqrt{\left(\left(x_{1}^{\mathrm{w}}\right)_{i}^{j}\right)^{2}+\left(\left(y_{1}^{\mathrm{w}}\right)_{i}^{j}\right)^{2}}\right)^{2}-\left(\left(z_{1}^{\mathrm{w}}\right)_{i}^{j}\right)^{2}=0
$$

The hourglass helix equation can be obtained by combined Eqs. (6) and (7).

The TI worm tooth surface can be turned on the turning center with rectangular turning tool, as shown in Fig. 3. The turning center has three numerically closed-loop controlled axis: the longitudinal rectilinear motion axis $X$, the transversal rectilinear motion axis $Z$ and the rotational motion axis $C$.

Based on the rotation of TI worm and the translation of turning tool, the hourglass helix on the right tooth surface can be generated by the endpoint of rectangular turning tool, the front blade and the right blade of rectangular turning tool will generate the groove. The whole tooth surface will be turned, while the turning locus from the tip to the root. It is the same principle to turning the left tooth surface.

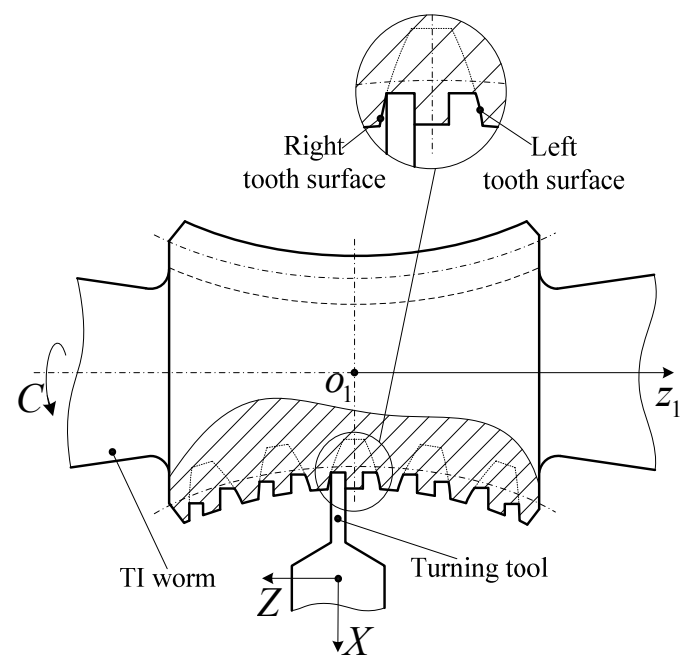

Fig. 3 Schematic of turning tooth surface

In order to reduce shock and improve meshing performance, different types of modifications(Zhao, Kong et al. 2011) and end relief are always required in the TI worm drive. The turning method developed and mentioned above is 
also appropriate for the modified TI worm tooth surface.

\subsection{Tooth thickness control}

Because of the symmetry of two sides of TI worm tooth surfaces, one side of tooth surface or hourglass helix can be transformed from the other one, as shown in Fig. 4.

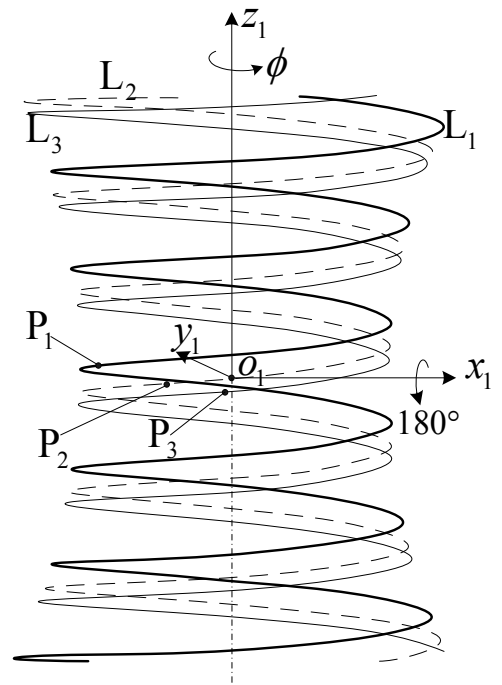

(a) Curves in $\sigma_{1}$

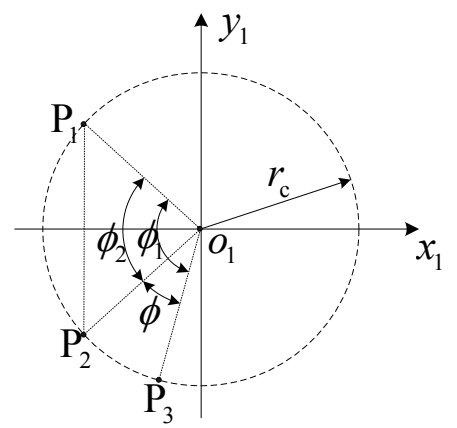

(b) Points on throat plane

Fig. 4 Transformation of hourglass helix

In Fig. 4(a), curve $\mathrm{L}_{1}$ is an hourglass helix on the right tooth surface of TI worm. Curve $\mathrm{L}_{2}$ is an auxiliary hourglass helix, and it is transformed from curve $\mathrm{L}_{1}$ by rotate $180^{\circ}$ about the $x_{1}$ axis. Curve $\mathrm{L}_{3}$ is an hourglass helix on the left tooth surface of TI worm, and it is transformed from curve $\mathrm{L}_{2}$ by rotate $\phi$ about the $z_{1}$ axis. $\mathrm{P}_{1}, \mathrm{P}_{2}$ and $\mathrm{P}_{3}$ are the intersection points on throat plane of curve $\mathrm{L}_{1}$, curve $\mathrm{L}_{2}$ and curve $\mathrm{L}_{3}$, respectively.

Based on Eqs. (6) and (7), the coordinate values of curve $\mathrm{L}_{1}$ on the right tooth surface can be calculated as $\left(x_{1}{ }^{\text {wr }}\right.$, $y_{1}{ }^{\mathrm{wr}}, z_{1}{ }^{\mathrm{wr}}$ ) in coordinate system $\sigma_{1}$. The coordinate values of left tooth surface curve $\mathrm{L}_{3}$ in coordinate system $\sigma_{1}$ can be represented as following:

$$
\left.\begin{array}{l}
x_{1}^{\mathrm{wl}}=x_{1}^{\mathrm{wr}} \cos \phi+y_{1}^{\mathrm{wr}} \sin \phi \\
y_{1}^{\mathrm{wl}}=x_{1}^{\mathrm{wr}} \sin \phi-y_{1}^{\mathrm{wr}} \cos \phi \\
z_{1}^{\mathrm{wl}}=-z_{1}^{\mathrm{wr}}
\end{array}\right\}
$$

where $\phi$ is the tooth thickness angle. It is illustrated in Fig. 4(b) and will be stated below.

In Fig. $4(\mathrm{~b}), r_{\mathrm{c}}$ is the radius of hourglass helix on throat plane. And it can be represented as following:

$$
r_{\mathrm{c}}=a-r_{\mathrm{a}}+h_{\mathrm{n}}
$$

where $h_{\mathrm{n}}$ is chordal height.

Substituting $r_{\mathrm{i}}=r_{\mathrm{c}}$ and $\left(z_{1}{ }^{\mathrm{w}}\right)_{\mathrm{i}}^{\mathrm{j}}=0$ into Eq. (7), and combined with Eq. (6), the coordinate values of point $\mathrm{P}_{1}$ can be calculated as $\left(\left(x_{1}\right)_{\mathrm{p} 1}^{\mathrm{w}},\left(y_{1}{ }^{\mathrm{w}}\right)_{\mathrm{p} 1}, 0\right)$.

The tooth thickness angle can be represented as:

$$
\phi=\phi_{1}-\phi_{2}
$$

where

$$
\begin{aligned}
& \phi_{1}=\frac{s_{\mathrm{n}}}{r_{\mathrm{c}} \sin \left(\arctan \left(\left(a-r_{\mathrm{c}}\right) /\left(r_{\mathrm{c}} i_{12}\right)\right)\right)}, \\
& \phi_{2}= \begin{cases}\pi & \left(\left(x_{1}^{\mathrm{w}}\right)_{\mathrm{p} 1}=0\right) \\
-2 \arctan \left(\left(y_{1}^{\mathrm{w}}\right)_{\mathrm{p} 1} /\left(x_{1}^{\mathrm{w}}\right)_{\mathrm{p} 1}\right) & \left(\left(x_{1}^{\mathrm{w}}\right)_{\mathrm{p} 1} \neq 0\right)\end{cases}
\end{aligned}
$$

$s_{\mathrm{n}}$ is the normal chordal tooth thickness on the throat plane. 


\subsection{NC programming}

To generate the hourglass helix on the turning center, the hourglass helix should be divided into a series of discretization points, and fitting each two adjacent discretization points with taper helix, as shown in Fig. 5.

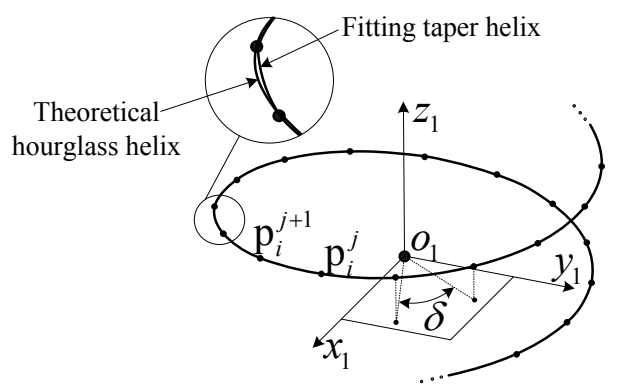

Fig. 5 Discretization and fitting of hourglass helix

In Fig. 5, $\delta$ is named as discretization angle, which is the transverse angle between each two adjacent discretization points. The coordinate values of discretization points $p_{i}^{\mathrm{j}}$ and $p_{i}^{\mathrm{j}+1}$ in coordinate system $\sigma_{1}$ are $\left(\left(x_{1}{ }^{\mathrm{w}}\right)_{i}^{\mathrm{j}},\left(y_{1}{ }^{\mathrm{w}}\right)_{i}^{\mathrm{j}},\left(z_{1}{ }^{\mathrm{w}}\right)_{i}^{\mathrm{j}}\right)^{\mathrm{j}}$ and $\left(\left(x_{1}{ }^{\mathrm{w}}\right)_{i}^{\mathrm{j}+1},\left(y_{1}{ }^{\mathrm{w}}\right)_{\mathrm{i}}^{\mathrm{j}+1},\left(z_{1}{ }^{\mathrm{w}}\right)_{\mathrm{i}}^{\mathrm{j}+1}\right)$, respectively. The NC program between discretization points $\mathrm{p}_{i}^{\mathrm{j}}$ and $\mathrm{p}_{\mathrm{i}}^{\mathrm{j}+1}$ can be represented as following:

$$
\mathrm{G} 01 \quad \mathrm{U}\left(u_{i}^{j}\right) \quad \mathrm{W}\left(w_{i}^{j}\right) \quad \mathrm{H}(\delta)
$$

where

$$
\begin{aligned}
& u_{i n}=2\left(\sqrt{\left(\left(x_{1}^{\mathrm{w}}\right)_{i}^{j+1}\right)^{2}+\left(\left(y_{1}^{\mathrm{w}}\right)_{i}^{j+1}\right)^{2}}-\sqrt{\left(\left(x_{1}^{\mathrm{w}}\right)_{i}^{j}\right)^{2}+\left(\left(y_{1}^{\mathrm{w}}\right)_{i}^{j}\right)^{2}}\right), \\
& w_{i}^{j}=\left(z_{1}^{\mathrm{w}}\right)_{i}^{j+1}-\left(z_{1}^{\mathrm{w}}\right)_{i}^{j} .
\end{aligned}
$$

\section{Accuracy analysis}

The turning accuracy of TI worm tooth surface, mainly depends on the amount of feed $\Delta r$ and the discretization angle $\delta$. In theory, the smaller of feed-rate and discretization angle, the higher accuracy of turning tooth surface. However, it will increase NC codes and also decrease processing efficiency with the smallest values. Therefore, it is necessary to choose the reasonable values of feed-rate and discretization angle to achieve the available turning accuracy.

Turning accuracy of a TI worm without modification will be analyzed. The main parameters of TI worm drive are given in Table 1.

Table 1 Main parameters of TI worm drive

\begin{tabular}{cll}
\hline \hline Type & \multicolumn{1}{c}{ Parameters } & Values \\
\hline & Normal module, $m_{\mathrm{n}} / \mathrm{mm}$ & 5 \\
& Pressure angle, $\alpha /^{\circ}$ & 20 \\
& Number of gear teeth, $\mathrm{Z}_{2}$ & 40 \\
& Thread direction & Right \\
Involute gear & Helix angle, $\beta /{ }^{\circ}$ & 2.5 \\
& Addendum coefficient, $h_{\mathrm{a}}{ }^{*}$ & 1 \\
& Bottom clearance coefficient, $c^{*}$ & 0.25 \\
& Facewidth of gear, $b / \mathrm{mm}$ & 40 \\
\hline
\end{tabular}




\begin{tabular}{lll}
\hline & Center distance, $a / \mathrm{mm}$ & 125 \\
& Number of worm threads, $\mathrm{Z}_{1}$ & 1 \\
Thread direction & Right \\
\multirow{3}{*}{ TI worm } & Arc radius of tip circle, $r_{\mathrm{a}} / \mathrm{mm}$ & 95 \\
& Arc radius of root circle, $r_{\mathrm{f}} / \mathrm{mm}$ & 106.25 \\
& Chordal height, $h_{\mathrm{n}} / \mathrm{mm}$ & 5 \\
& Normal chordal tooth thickness, $s_{\mathrm{n}} / \mathrm{mm}$ & 6.52 \\
& Effective length of worm tooth, $l / \mathrm{mm}$ & 80 \\
\hline
\end{tabular}

\subsection{Tooth profile error}

The turning tooth surface of TI worm is discretized into a series of hourglass helixes, and there is a piend between each two adjacent hourglass helixes, as shown in Fig. 6.

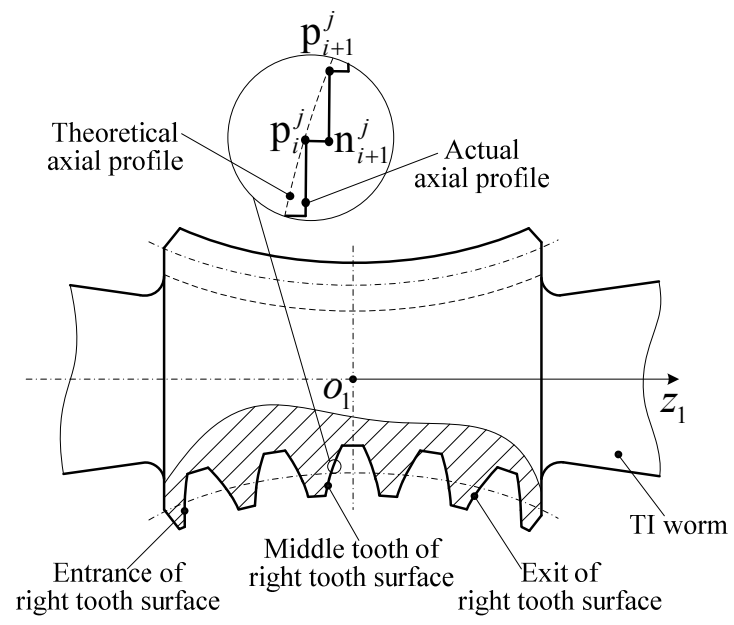

Fig. 6 Schematic of axial profile error

In Fig. 6, points $p_{i}^{j}$ and $p_{i+1}{ }^{j}$ on the theoretical axial profile, lines $p_{i}^{j} n_{i+1}{ }^{j}$ and $p_{i+1}{ }^{j} n_{i+1}{ }^{j}$ are the actual axial profile, and point $n_{i+1}{ }^{j}$ is the piend. The coordinate values of points $p_{i}^{j}$ and $p_{i+1}{ }^{j}$ in coordinate system $\sigma_{1}$ are $\quad\left(\left(x_{1}{ }^{w}\right)_{i}^{j},\left(y_{1}{ }^{w}\right)_{i}^{j},\left(z_{1}{ }^{w}\right)_{i}^{j}\right)$ and $\left.\left(\left(x_{1}\right)^{\mathrm{w}}\right)_{\mathrm{i}+1}^{\mathrm{j}},\left(y_{1}{ }^{\mathrm{w}}\right)_{i+1} \mathrm{j},\left(z_{1}{ }^{\mathrm{w}}\right)_{\mathrm{i}+1}^{\mathrm{j}}\right)$, respectively.

Based on the smaller amount of feed $\Delta r$, curve $\mathrm{p}_{\mathrm{i}}^{\mathrm{j}} \mathrm{p}_{\mathrm{i}+1}^{\mathrm{j}}$ can be considered as a line. Therefore, the length of line $p_{i}^{j} p_{i+1}^{j}$ can be represented as following:

$$
l_{i+1}^{j}=\sqrt{\left(\left(x_{1}\right)_{i}^{j}-\left(x_{1}\right)_{i+1}^{j}\right)^{2}+\left(\left(y_{1}\right)_{i}^{j}-\left(y_{1}\right)_{i+1}^{j}\right)^{2}+\left(\left(z_{1}\right)_{i}^{j}-\left(z_{1}\right)_{i+1}^{j}\right)^{2}}
$$

In right-angled triangle $\mathrm{p}_{\mathrm{i}}^{\mathrm{j}} \mathrm{n}_{\mathrm{i}+1}{ }^{\mathrm{j}} \mathrm{p}_{\mathrm{i}+1} \mathrm{j}^{\mathrm{j}}$, the areas of it can be represented as following:

$$
S_{i+1}^{j}=\frac{1}{2}\left|\left(z_{1}\right)_{i}^{j}-\left(z_{1}\right)_{i+1}^{j}\right|\left|\sqrt{\left(\left(x_{1}\right)_{i}^{j}\right)^{2}+\left(\left(y_{1}\right)_{i}^{j}\right)^{2}}-\sqrt{\left(\left(x_{1}\right)_{i+1}^{j}\right)^{2}+\left(\left(y_{1}\right)_{i+1}^{j}\right)^{2}}\right|
$$

Therefore, the roughness on this axial profile can be represented as following:

$$
(R a)^{j}=\frac{\sum_{i=1}^{i_{\max }-1} S_{i+1}^{j}}{\sum_{i=1}^{i_{\max }-1} l_{i+1}^{j}}
$$

where $i_{\max }$ is the maximum number of hourglass helix sequence number in tooth surface.

The height of the base in the right-angled triangle $p_{i}^{j} n_{i+1}^{j} p_{i+1}^{j}$, which also is the tooth profile error in the microcosmic region, can be represented as following: 


$$
h_{i+1}^{j}=\frac{2 S_{i+1}^{j}}{l_{i+1}^{j}}
$$

Therefore, the maximum tooth profile deviation in this axial profile can be represented as following:

$$
\left(R_{z}\right)^{j}=\max \left\{h_{2}^{j}, h_{3}^{j} \cdots h_{i_{\max }^{j}}^{j}\right\}
$$

A TI worm with the main parameters in Table 1 is calculated and analyzed. The influence curves of tooth profile error with amount of feed are shown in Fig. 7.

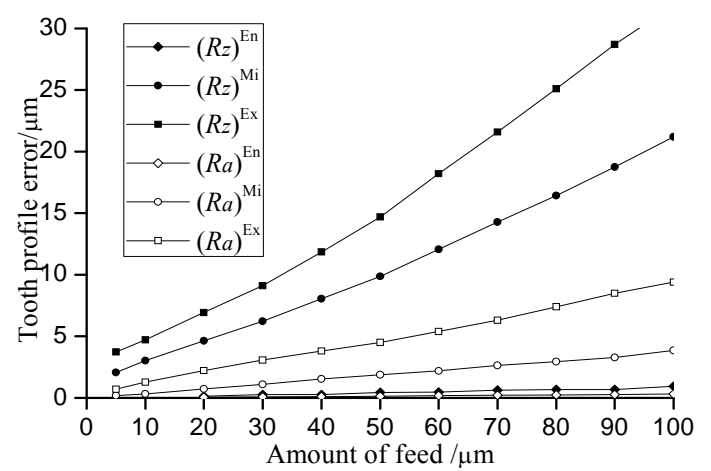

Fig. 7 Influence curves of tooth profile error with amount of feed

In Fig. 7, $(R z)^{\mathrm{En}} 、(R z)^{\mathrm{Mi}} 、(R z)^{\mathrm{Ex}}$ are the maximum tooth profile deviation on the entrance, middle tooth and exit of right tooth surface, respectively. $(R a)^{\mathrm{En}} 、(R a)^{\mathrm{Mi}} 、(R a)^{\mathrm{Ex}}$ are the roughness on the entrance, middle tooth and exit of right tooth surface, respectively.

Some conclusions can be obtained as followings according to Fig. 7:

(1) The maximum tooth profile deviation and roughness on the entrance is far less than those on the middle tooth and exit of the tooth surface. The small tooth profile deviation and roughness in the entrance is because of that the cutting tool is perpendicular to the axis of TI worm, as shown in Fig. 3, and the axial tooth profile in the entrance is also almost perpendicular to the axis of TI worm, as shown in Fig. 6 . While the axial tooth profile in the exit is incline to the axis of TI worm, and bring about big tooth profile deviation and roughness.

(2) When the amount of feed is $0.01 \mathrm{~mm}$, the roughness can up to $1.6 \mu \mathrm{m}$ and the maximum tooth profile deviation will less than $5 \mu \mathrm{m}$ on the whole tooth surface.

(3) When the amount of feed is $0.1 \mathrm{~mm}$, the roughness will exceed $6.3 \mu \mathrm{m}$ and the maximum tooth profile deviation will greater than $30 \mu \mathrm{m}$ on the whole tooth surface.

\subsection{Discretization error}

As shown in Fig. 4, the hourglass helix was divided into a series of discretization points, and each two adjacent discretization points were fitted with taper helix. The deviations between the theoretical hourglass helix and the fitting taper helix are shown in Fig. 8. $\mathrm{t}_{\mathrm{i}}^{\mathrm{n}}$ is a calculated point on the theoretical hourglass helix, and it is between discretization points $p_{i}^{j}$ and $p_{i}^{j+1}$. $f_{i}^{n}$ is a correspondence point of $t_{i}^{n}$ on the fitting taper helix. 


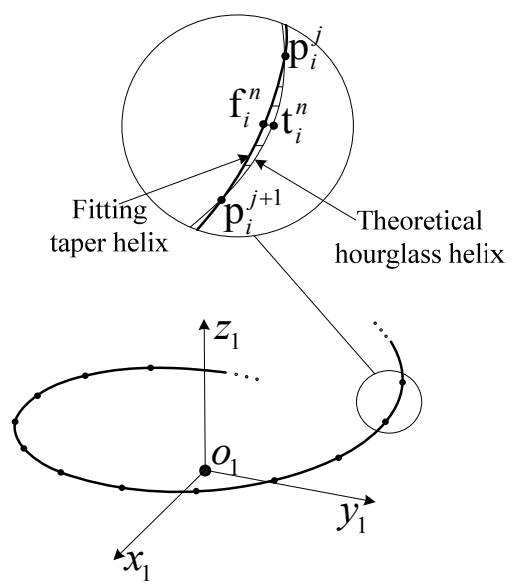

Fig. 8 Schematic of discretization error

The coordinate values of calculated point $t_{i}^{\mathrm{n}}$ can be represented as $\left(\left(x_{1}{ }^{\mathrm{w}}\right)_{\mathrm{i}}^{\mathrm{n}},\left(y_{1}{ }^{\mathrm{w}}\right){ }_{\mathrm{i}^{\mathrm{n}}}^{\mathrm{n}},\left(z_{1}{ }^{\mathrm{w}}\right){ }^{\mathrm{n}}\right)$. Therefore, the coordinate values of correspondence point $\mathrm{f}_{\mathrm{i}}^{\mathrm{n}}$ can be represented as following:

$$
\left.\begin{array}{l}
\left(x_{1}^{\mathrm{f}}\right)_{i}^{n}=r_{i}^{n} \cos \left(\left(\varphi_{1}\right)_{i}^{n}-\left(\varphi_{2}\right)_{i}^{n}\right) \\
\left(y_{1}^{\mathrm{f}}\right)_{i}^{n}=r_{i}^{n} \sin \left(\left(\varphi_{1}\right)_{i}^{n}-\left(\varphi_{2}\right)_{i}^{n}\right) \\
\left(z_{1}^{\mathrm{f}}\right)_{i}^{n}=\left(z^{\mathrm{w}}\right)_{i}^{n}
\end{array}\right\}
$$

where

$$
\begin{aligned}
& \left(\varphi_{1}\right)_{i}^{n}= \begin{cases}\arccos \left(\left(x_{1}^{\mathrm{w}}\right)_{i}^{j} / \sqrt{\left(\left(x_{1}^{\mathrm{w}}\right)_{i}^{j}\right)^{2}+\left(\left(y_{1}^{\mathrm{w}}\right)_{i}^{j}\right)^{2}}\right. & \left(y_{1}^{\mathrm{w}}\right)_{i}^{j}>0 \\
2 \pi-\arccos \left(\left(x_{1}^{\mathrm{w}}\right)_{i}^{j} / \sqrt{\left(\left(x_{1}^{\mathrm{w}}\right)_{i}^{j}\right)^{2}+\left(\left(y_{1}^{\mathrm{w}}\right)_{i}^{j}\right)^{2}}\right. & \left(y_{1}^{\mathrm{w}}\right)_{i}^{j}<0,\end{cases} \\
& \left(\varphi_{2}\right)_{i}^{n}=\frac{\left(z_{1}^{\mathrm{w}}\right)_{i}^{n}-\left(z_{1}^{\mathrm{w}}\right)_{i}^{j}}{\left(z_{1}^{\mathrm{w}}\right)_{i}^{j+1}-\left(z_{1}^{\mathrm{w}}\right)_{i}^{j}} \delta, \\
& r_{i}^{n}=\sqrt{\left(\left(x_{1}^{\mathrm{w}}\right)_{i}^{j}\right)^{2}+\left(\left(y_{1}^{\mathrm{w}}\right)_{i}^{j}\right)^{2}}+\frac{\sqrt{\left(\left(x_{1}^{\mathrm{w}}\right)_{i}^{j+1}\right)^{2}+\left(\left(y_{1}^{\mathrm{w}}\right)_{i}^{j+1}\right)^{2}}-\sqrt{\left(\left(x_{1}^{\mathrm{w}}\right)_{i}^{j}\right)^{2}+\left(\left(y_{1}^{\mathrm{w}}\right)_{i}^{j}\right)^{2}}}{\delta}\left(\varphi_{2}\right)_{i}^{n}
\end{aligned}
$$

The discretization error at calculated point $\mathrm{t}_{\mathrm{i}}^{\mathrm{n}}$ can be defined as:

$$
e_{i}^{n}=\sqrt{\left(\left(x_{1}^{\mathrm{w}}\right)_{i}^{n}-\left(x_{1}^{\mathrm{f}}\right)_{i}^{n}\right)^{2}+\left(\left(y_{1}^{\mathrm{w}}\right)_{i}^{n}-\left(y_{1}^{\mathrm{f}}\right)_{i}^{n}\right)^{2}}
$$

Therefore, the maximum discretization deviation in this hourglass helix can be represented as following:

$$
\left(R_{z}\right)_{i}=\max \left\{e_{i}^{1}, e_{i}^{2} \cdots e_{i}^{n_{\max }}\right\}
$$

where $n_{\max }$ is the maximum number of calculated point on the hourglass helix.

The roughness on this hourglass helix can be represented as following:

$$
(R a)_{i}=\frac{\sum_{n=1}^{n_{\max }} e_{i}^{n}}{n_{\max }}
$$

A TI worm with the main parameters in Table 1 is calculated and analyzed. The influence curves of tooth profile error with discretization angle are shown in Fig. 9. 


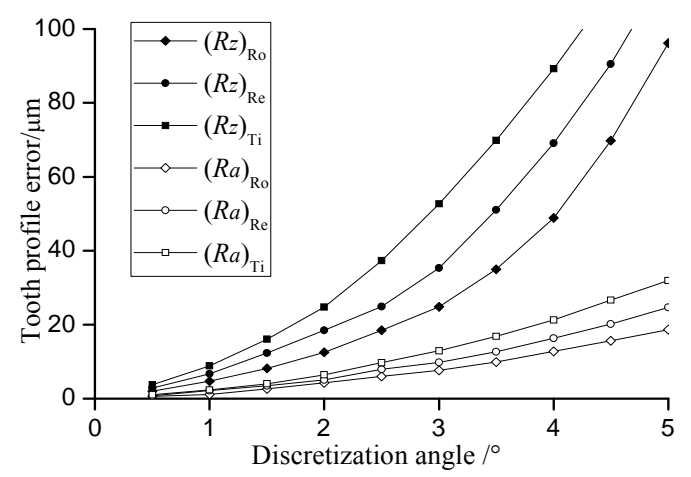

Fig. 9 Influence curves of tooth profile error with discretization angle

In Fig. 9, $(R z)_{\mathrm{Ro}},(R z)_{\mathrm{Re}},(R z)_{\mathrm{Ti}}$ are the maximum tooth profile deviation on root circle hourglass helix, reference circle hourglass helix and tip circle hourglass helix of right tooth surface, respectively. $(R a)_{\mathrm{Ro}},(R a)_{\mathrm{Re}},(R a)_{\mathrm{Ti}}$ are the roughness on root circle hourglass helix, reference circle hourglass helix and tip circle hourglass helix of right tooth surface, respectively.

Some conclusions can be obtained as followings according to Fig. 9:

(1) The maximum tooth profile deviation and roughness on the tip circle hourglass helix of tooth surface are the biggest, and those on root circle hourglass helix of tooth surface are the smallest. Those because of that the radius of tip circle hourglass helix is bigger than that of root circle hourglass helix, and the distance between adjacent discretization points in the tip circle hourglass helix is also longer than that in the root circle hourglass helix.

(2) When the discretization angle is $0.5^{\circ}$, the roughness can up to $1.6 \mu \mathrm{m}$ and the maximum tooth profile deviation will less than $3.5 \mu \mathrm{m}$ on the whole tooth surface.

\section{Turing example}

To verify the correctness and practicability of the aforementioned turning method, a nylon TI worm with the main parameters in Table 1 is turned and the contact pattern of TI worm drive is checked by red test.

A turning center CH460 with the operating system of FANUC Series 0i-TC is used, the amount of feed is selected as $\Delta r=0.1 \mathrm{~mm}$ and the discretization angle is selected as $\delta=1^{\circ}$. The turning process of TI worm tooth surface is shown in Fig. 10(a) and Fig. 10(b). The finished product is shown in Fig. 10(c).

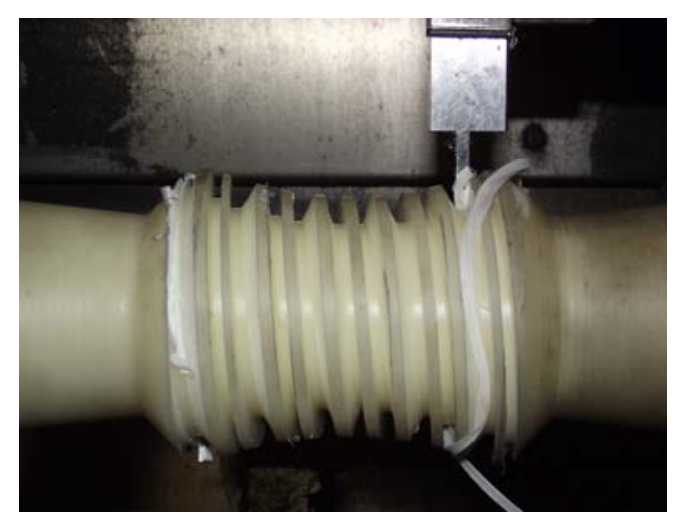

(a) Turning I

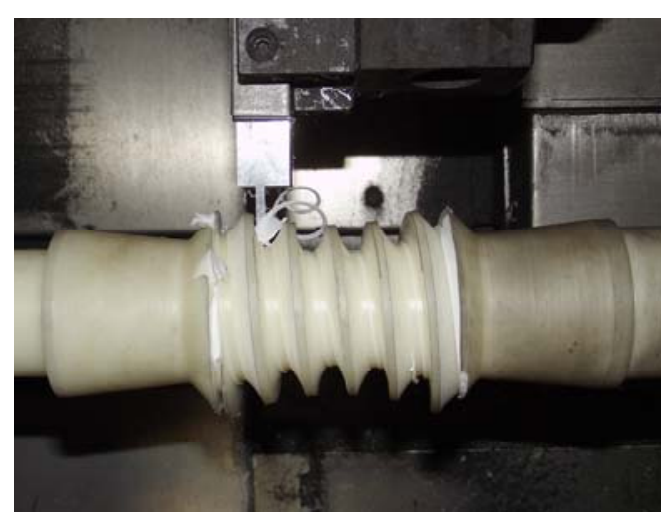

(b) Turning II 


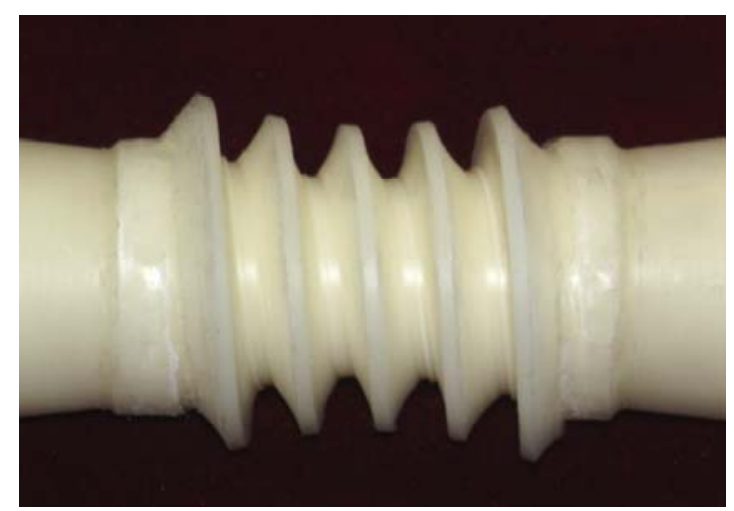

(c) Finished product

Fig. 10 Turning of TI worm tooth surface

Based on the meshing function Eq.(5) and the involute gear surface equation Eq.(1), the instantaneous contact lines and theoretical meshing area of the TI worm drive are shown in Fig. 11(a). In order to obtain the actual contact pattern(Mohan and Shunmugam 2009), a hobbing machine Y3180H which is manufactured by the Chongqing Machine Tool Group Co., Ltd is used to check the tooth accuracy. The TI worm is mounted and locked on the tool holder of hobbing machine $\mathrm{Y} 3180 \mathrm{H}$, and the involute gear is mounted freely on the worktable of hobbing machine $\mathrm{Y} 3180 \mathrm{H}$. The center distance is maintained and involute gear is centered and positioned with respect to the TI worm in the vertical and horizontal directions. Red lead powder is applied on the TI worm tooth, and the TI worm is rotated in mesh with the involute gear. Fig. 11(b) shows the actual contact pattern obtained on the involute gear. It indicates that the actual contact pattern is established on the left side of the tooth surface, and this is in accord with the theoretical meshing area. The results show the high accuracy profile of turning TI worm tooth surface, the correctness and practicability of the turning method.

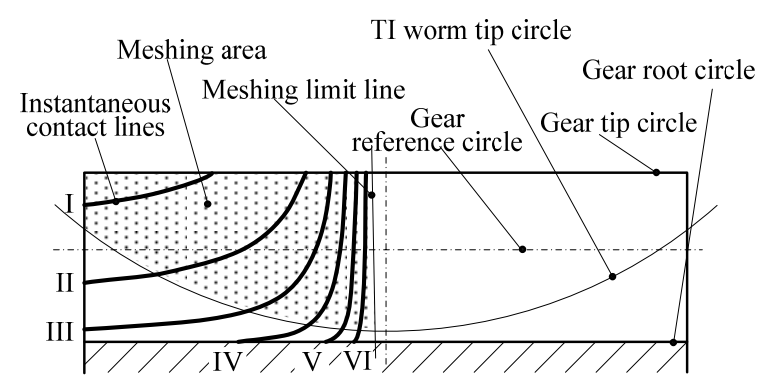

(a) Theoretical meshing area

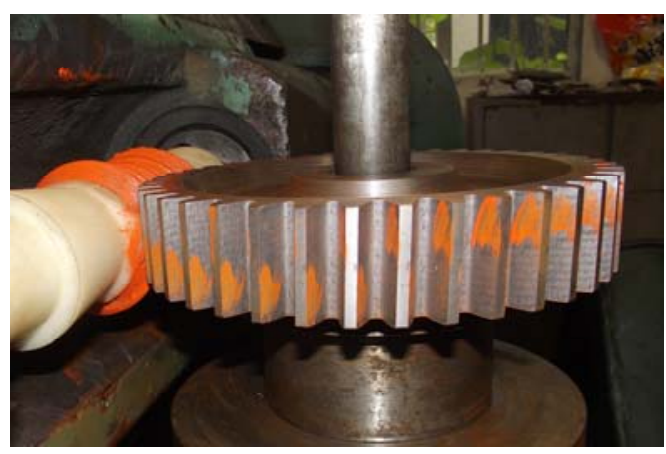

(b) Actual contact pattern

Fig. 11. Meshing area and contact pattern

\section{Conclusions}

Presented is an accurately turning method of TI worm tooth surface. Based on the performed research, the following conclusions may be drawn:

(1) To turning the TI worm tooth surface, it was decomposed into a series of hourglass helixes. Each hourglass helix was divided into a series of discretization points, and each two adjacent discretization points were fitted with taper helix, which is generated by turning tool endpoint of turning center.

(2) The tooth profile deviation and roughness on the entrance is far less than those on the middle tooth and exit of the tooth surface.

(3) The maximum tooth profile deviation and roughness on the tip circle hourglass helix of tooth surface are the biggest, and those on root circle hourglass helix of tooth surface are the smallest.

(4) When the amount of feed is $0.01 \mathrm{~mm}$ and the discretization angle is $0.5^{\circ}$, the roughness can up to $1.6 \mu \mathrm{m}$ and the 
maximum tooth profile deviation will less than $3.5 \mu \mathrm{m}$ on the whole tooth surface, which can be accepted by the power worm drive.

(5) The correctness and practicability of the proposed turning method are verified by the turning example and the red test.

The study is expected to provide theoretical and experimental foundation for the future explore the accurately hard turning of TI worm tooth surface. It conduces to the promotion and application of TI worm drive.

\section{Acknowledgment}

This work was supported by the National Natural Science Foundation of China (Grant No. 51405394), the Applied Basic Research Program of Sichuan Provincial Science and Technology Department (Grant No. 2014JY0129), the Chun Hui Project (Grant No. Z2014074).

\section{Nomenclature}

a Center distance of the TI worm drive, (mm)

$Z_{1}, Z_{2} \quad$ Number of TI worm threads and involute gear teeth, respectively

$i_{12} \quad$ Gearing ratio of the TI worm drive, here $i_{12}=Z_{2} / Z_{1}$

$i_{21} \quad$ Teeth ratio of the TI worm drive, here $i_{12}=1 / i_{12}$

$\sigma_{\mathrm{m}}, \sigma_{\mathrm{n}} \quad$ Fixed coordinate systems

$\sigma_{1}, \sigma_{2} \quad$ Movable coordinate systems

$\boldsymbol{\omega}_{1}, \boldsymbol{\omega}_{2} \quad$ Angular velocity of the TI worm and involute gear, respectively, $(\mathrm{rad} / \mathrm{s})$

$\varphi_{1}, \varphi_{2} \quad$ Rotating angles of the TI worm and involute gear, respectively, $\left({ }^{\circ}\right)$

$\boldsymbol{i}_{i}, \boldsymbol{j}_{i}, \boldsymbol{k}_{i} \quad$ Unit vector of coordinate systems $\sigma_{i}(i=1,2, \mathrm{~m}, \mathrm{n})$

$\Sigma^{\mathrm{w}}, \Sigma^{\mathrm{g}} \quad$ Tooth surface of the TI worm and involute gear, respectively

$r_{\mathrm{b}} \quad$ Radius of base circle, $(\mathrm{mm})$

$u, \theta \quad$ Surface variable parameters of $\Sigma^{\mathrm{g}}$

$p \quad$ Lead-per-radian revolution of $\Sigma^{\mathrm{g}}$

$\boldsymbol{r}^{\mathrm{g}}, \boldsymbol{r}^{\mathrm{w}} \quad$ Position vector of $\Sigma^{\mathrm{g}}$ and $\Sigma^{\mathrm{w}}$, respectively

$v^{\mathrm{gw}} \quad$ Relative velocity vector between TI worm and involute gear, $(\mathrm{mm} / \mathrm{s})$

$n^{\mathrm{g}} \quad$ Unit normal vector of $\Sigma^{\mathrm{g}}$

$\Phi \quad$ Meshing function

$r_{\mathrm{i}} \quad$ Radius of the hourglass helix, (mm)

$r_{\mathrm{a}}, r_{\mathrm{f}} \quad$ Radius of tip circle and root circle, respectively, (mm)

$\mathrm{p}_{\mathrm{i}}^{\mathrm{j}} \quad$ No. $j$ discretization point on the No. $i$ hourglass helix

$x_{1}{ }^{\mathrm{wl}}, y_{1}{ }^{\mathrm{wl}}, z_{1}{ }^{\mathrm{wl}}$ Coordinate values on the left tooth surface of TI worm, (mm)

$x_{1}{ }^{\mathrm{wr}}, y_{1}{ }^{\mathrm{wr}}, z_{1}{ }^{\mathrm{wr}}$ Coordinate values on the right tooth surface of TI worm, (mm)

$\phi \quad$ Tooth thickness angle, $\left({ }^{\circ}\right)$

$h_{\mathrm{n}} \quad$ Chordal height, $(\mathrm{mm})$

$s_{\mathrm{n}} \quad$ Normal chordal tooth thickness on the throat plane, $(\mathrm{mm})$

$\Delta r \quad$ Amount of feed, $(\mathrm{mm})$

$\delta \quad$ Discretization angle, $\left({ }^{\circ}\right)$

$m_{\mathrm{n}} \quad$ Normal module of involute gear, $(\mathrm{mm})$

$\alpha \quad$ Pressure angle of involute gear, $\left({ }^{\circ}\right)$

$\beta \quad$ Helix angle of involute gear, $\left({ }^{\circ}\right)$

$h_{\mathrm{a}}{ }^{*} \quad$ Addendum coefficient of involute gear

$c^{*} \quad$ Bottom clearance coefficient of involute gear

$b \quad$ Facewidth of involute gear, $(\mathrm{mm})$

$l \quad$ Effective length of TI worm tooth, $(\mathrm{mm})$

$\left(x_{1}{ }^{\mathrm{w}}\right)_{\mathrm{i}}^{\mathrm{j}},\left(y_{1}{ }^{\mathrm{w}}\right)_{\mathrm{i}}^{\mathrm{j}},\left(z_{1}{ }^{\mathrm{w}}\right)_{\mathrm{i}}^{\mathrm{j}} \quad$ Coordinate values on the discretization point $\mathrm{p}_{\mathrm{i}}^{\mathrm{j}},(\mathrm{mm})$

$(R z)^{\mathrm{En}},(R z)^{\mathrm{Mi}},(R z)^{\mathrm{Ex}} \quad$ Maximum tooth profile deviation on the entrance, middle tooth and exit of thetooth surface, 
respectively, $(\mu \mathrm{m})$

$(R a)^{\mathrm{En}},(R a)^{\mathrm{Mi}},(R a)^{\mathrm{Ex}} \quad$ Roughness on the entrance, middle tooth and exit of thetooth surface, respectively, $(\mu \mathrm{m})$

$(R z)_{\mathrm{Ro}},(R z)_{\mathrm{Re}},(R z)_{\mathrm{Ti}}$ Maximum tooth profile deviation on root circle hourglass helix, reference circle hourglass helix and tip circle hourglass helix of the tooth surface, respectively, $(\mu \mathrm{m})$

$(R a)_{\mathrm{Ro}},(R a)_{\mathrm{Re}},(R a)_{\mathrm{Ti}} \quad$ Roughness on root circle hourglass helix, reference circle hourglass helix and tip circle hourglass helix of the tooth surface, respectively, $(\mu \mathrm{m})$

\section{References}

Chen, K. Y. and Tsay, C. B., Mathematical model and worm wheel tooth working surfaces of the ZN-type hourglass worm gear set, Mechanism and Machine Theory, Vol. 44, No. 9(2009), pp.1701-1712.

Chen, Y. H., Chen, Y., Wang, J. G. and Zhang, G. H., Manufacturing and measuring investigation of crown worm tooth surface, Journal of Advanced Mechanical Design Systems and Manufacturing, Vol. 9, No. 1(2015), DOI: 10.1299/jamdsm.2015jamdsm0003.

Chen, Y. H., Zhang, G. H., Chen, B. K., Luo, W. J., Li, F. J. and Chen, Y., A novel enveloping worm pair via employing the conjugating planar internal gear as counterpart, Mechanism and Machine Theory, Vol. 67(2013), pp.17-31.

Dong, L. Y., Wang, J. Y., Liu, P. Y., Wei, W. J. and Li, H. T., An NC rough turning method of an enveloping toroidal worm, Production Engineering, Vol. 6, No. 2(2012), pp.129-135.

Huang, Z. and Xu, L., Design and Manufacture for Toroidal Drive, Proceedings of the Institution of Mechanical Engineers, Part B: Journal of Engineering Manufacture, Vol. 221, No. 2(2007), pp.347-353.

Litvin, F. L. and Fuentes, A., Gear geometry and applied theory, second edition. New York, Cambridge University Press, (2004), pp.158-170.

Liu, H., Theoretical study on enveloped worm drives based on involute gear-like dressing-gear and a new method to process TI worm of high precision, Tianjin, Tianjin University. Ph.D., (2001), pp. 1-78(in Chinese).

Maki, M., Okamoto, K. and Midorikawa, I., A study on the hourglass worm gearing whose wheel has the helical teeth(1st report), Transactions of the Japan Society of Mechanical Engineers, Part C, Vol. 61, No. 582(1995), pp.362-366(in Japanese).

Mohan, L. V. and Shunmugam, M. S., Geometrical aspects of double enveloping worm gear drive, Mechanism and Machine Theory, Vol. 44, No. 11(2009), pp. 2053-2065.

Okamoto, K. and Maki, M., A study on the hourglass worm gearing whose wheel has the helical teeth(2nd report), Transactions of the Japan Society of Mechanical Engineers, Part C, Vol. 62, No. 601(1996), pp. 3642-3646(in Japanese).

Sun, Y. H., Lu, H. W. and Wang, S. R., Profile of Grinding Wheel for Grinding TI Worm, Chinese Journal of Mechanical Engineering, Vol. 44, No. 2(2008), pp. 170-174(in Chinese).

Sun, Y. H., Lu, H. W., Yang, W. Y. and Li, G. Y., A Study on Manufacture and Experiment of Hardened TI Worm Gearing, Journal of Mechanical Engineering, Vol. 47, No. 09(2011), pp.182-186(in Chinese).

Wang, S. R, Zhan, D. A., Liu, H. and Wang, S. Y., Tooth contact analysis of toroidal involute worm mating with involute helical gear, Mechanism and Machine Theory, Vol. 37, No. 7(2002), pp. 685-691.

Wildhaber, E., Wildhaber worm drive, United States Patent 3386305, (1966).

$\mathrm{Xu}, \mathrm{L}$. and Huang, J., Torques for Electromechanical Integrating Toroidal Drive, Proceedings of the Institution of Mechanical Engineers, Part C: Journal of Mechanical Engineering Science, Vol. 219, No. 8(2005), pp. 801-811.

Yao, L., Dai, J. S. and Li, H., Mathematical modelling and manufacturing of the internal toroidal tooth profile, Proceedings of the Institution of Mechanical Engineers, Part C: Journal of Mechanical Engineering Science, Vol. 218, No. 9 (2004), pp. 1043-1051.

Zhang, G. H., Research and application of planar double-enveloping worm drive, Journal of Chongqing University, Vol. 1, No. 3(1978), pp. 1-18(in Chinese).

Zhao, Y. P., Kong, J. Y., Li, G. F. and Wu, T. C., Tooth flank modification theory of dual-torus double-enveloping hourglass worm drives, Computer-Aided Design, Vol. 43, No. 12(2011), pp. 1535-1544. 